\title{
THE ROLE OF COMPETITION AND TECHNOLOGY IN THE INNOVATIVENESS OF COMPANIES
}

\author{
*Arzu Karaman AKGUL \\ *Sitkı GOZLU \\ *Y1dız Technical University, Turkey, \\ ** Istanbul Technical University, Turkey.
}

\begin{abstract}
In today's highly competitive and dynamic markets firms having an intention to meet the changing needs of customers as soon as possible and nourishing innovative ideas by making use of appropriate technology may sustain and/or improve their competitiveness. The purpose of this study is to investigate the relationship between competition, technology, andinnovativeness of Turkish companies. A model that investigates the influence of technology and competition on innovativeness is developed. Hypotheses are developed and tested by conducting several statistical tests and techniques such as frequency analysis and logistic regression analysis. The results indicate that both competition and technology have a positive effect on the innovativeness of a company.
\end{abstract}

Keywords: Competition, Technology, Innovativeness

\section{INTRODUCTION}

Global competition is getting higher, markets and technology are changing rapidly, and complexities and uncertainties are increasing in the market, which results in the creation of a new competitive environment (Allison, 2002). In the industrial era, firms aimed to produce a narrow range of products, sustain economies of scale and achieve high productivity and low costs. In post-industrial era, organizations take the customer needs into the consideration and aim to develop production systems which design, produce and deliver high-value products to the customer (Brady, Clauser and Vaccari, 1997).

In such a competitive environment, firms have to cope with the pressures of their rivals and customers, and use a licensed technology in order to meet the changing needs of their customers against their competitors. The purpose of this study is to investigate the relationship between competition, technology, and innovativeness of Turkish companies. A model that investigates the influence of technology and innovativeness on quality is developed. Hypotheses are suggested and tested by conducting several statistical tests and techniques such as frequency analysis and logistic regression analysis.

The main aim of this study is to deal with the effects of technology and competition on innovativeness in manufacturing companies. In order to realize these aims, a model is developed based upon the literature regarding the concepts of technology, competition, and innovativeness. The constructs represented in the model are described in detail. Then, the model is tested by conducting several statistical tests and techniques such as frequency analysis and logistic regression analysis by using SPSS 16. In this study, the data gathered from Business Environment and Enterprise Performance Survey conducted by World Bank is used. It is collected from 1152 Turkish companies in 2008. Since the aim of this study is focusing on manufacturing companies, 860 of these 1152 companies who are operating in manufacturing industry are selected. There are some missing values in some questionnaires so that list wise deletion approach is applied. The cases with missing data are omitted and the analyses are run based on the remaining 643 questionnaire forms. The results indicate that all of the hypotheses are supported.

\section{LITERATURE REVIEW}

Enhancement of global competition, rapid changes of markets and technology, and increasing complexities and uncertainties in the market have given rise to a new competitive environment (Allison, 2002). Today's highly competitive and turbulent markets, shortened product lifecycles and rapid technological changes have made the technology a key source of competitiveness of a company (Erensal, Öncan ve Demircan, 2005; Ethier, 2005). As being an important contributor to success and the competitiveness of companies, technology, must be managed 
effectively and needs to be integrated to the firm's strategy. Technology provides firms improving their competitiveness whenever it is truly strategic. It means the appropriate licensed technology should be identified and consistent with the strategic plans and the investment of the appropriate technology should be formulated. While determining the technological needs of the firms, the technological resource skills and competencies should be considered (Hipkin and Bennett, 2003).

Technology is very significant for the companies since it provides sustainable competitive advantage, increases productivity, creates profits, protects from obsolescence, achieves business -market fit, enhances motivation and potential of employees, engine of economic growth, and improves quality of life (Hsuan, 1999). In order to transform their operations, companies using technology facilitate the emergence of new industries and create new sets of economic activities (Koufteros, Vonderembse and Doll, 2002).

Today's products and services are often technology based in order to fit customer's objectives, values, production system, lifestyle, use-pattern, and self-identity because technology has affected most business activities like manufacturing, administration, sales, distribution etc. by causing important changes (Krishnamacharyulu and Ramakrishnan,2008; Munir, 2003; Prajogo and Sohal, 2004). Managing technology effectively allows firms to enter new markets, renew existing product lines and keep up with rapid technological changes in the markets where they operate (Hipkin and Bennett, 2003). Technology may exist not only in tangible form such as machinery, tools, and equipment, but also in intangible forms such as knowledge, information, and know-how. According to the specific needs of a sector, industry or firm, different forms of technologies may be sought (Ethier, 2005). Companies need to manage technology investments effectively if they want to be a market leader. However it is a very costly investment, the role of technology in companies' competitiveness could not be ignored (Zehir et al., 2010).

Demands of customers are customized for high quality products, and manufacturing firms should response to these demands as quickly as possible (Allis on, 2012). Each firm has to introduce new and perhaps radically innovative products for surviving in such a highly competitive, dynamic, and uncertain environment (Reddy, 1997). This ability is called as innovation orientation and defined as being ready to be innovative (Ussahawanitchakit, 2008). Being innovative is related with firm performance and this relationship has been in the focus of several studies in the last decade. A study conducted in Turkey is also provides a strong evidence about this relationship between innovativeness and firm performance (Kocoglu, Imamoglu and Ince, 2011).

The aim of new product development process is to provide outstanding service to customers by manufacturing products of more variety and better suitability for customers' unique needs through responding without delay (Rungtus anathamand Forza, 2005). Nowadays, adjusting production methods globally and quickly in response to changes in the environment has become possible (Samaddar and Kadiyala, 2006).

Improving the new product development (NPD) process is one of the most important management challenges today. Succes sful new products not only contribute to financial and market performance measures, but also offer new opportunities to become visible (Schilling, 2005). Schumpeter (1947) was among the first economists who emphasized the importance of new products in economy. Since then, the studies related with the innovation area have defined different types of innovation that cover process innovations beside product innovation (Teitel, 2005; Tracey, Vonderembse and Lim, 1999; Trott, 2008). Thus, innovation can be defined as the management of all the activities involved in the process of idea generation, technology development, manufacturing, and marketing of a new (or improved) product or manufacturing process or equipment (Tseng, 2006).

Innovativeness is an important characteristic for all companies irrespective of their size and sector. Beside the large companies small and medium sized enterprises have to be innovative. There are also studies conducted in SMEs in Turkey and they find strong relationship between innovativeness and the performance of this companies' performance (Nedelko and Potocan, 2010; Kalkan, Bozkurt and Kılınç, 2012).

The most widely used typologies of innovation are product versus process innovations; radical versus incremental innovations; technological versus administrative innovations and architectural versus modular innovations. However, the commonly used classification is the typology of product and process innovations. While product innovation can be defined as tangible objects that deliver a new level of performance to customers, process innovation is defined as the way an organization conducts its business (Zhang, Vonderembse and Lim, 2003). In this study, product and process innovations are used for measuring innovativeness since this typology is more objective than the other dimensions and also easy to observe. 


\section{METHODOLOGY}

Intense global competition, changing customer expectations and the employment of advanced manufacturing technologies makes the environment more complex and uncertain [21, 22]. In order to sustain their competitiveness, firms have to review their competition strategies and use advanced technologies. Companies adopt a variety of strategies to attain the technological edge in their market so to gain or maintain their competitiveness in the global market (Erensal, Öncan and Demircan, 2005; Ethier, 2005). Based on literature review the hypotheses stated below are determined and the developed research model is based on these relations as illustrated in Figure I.

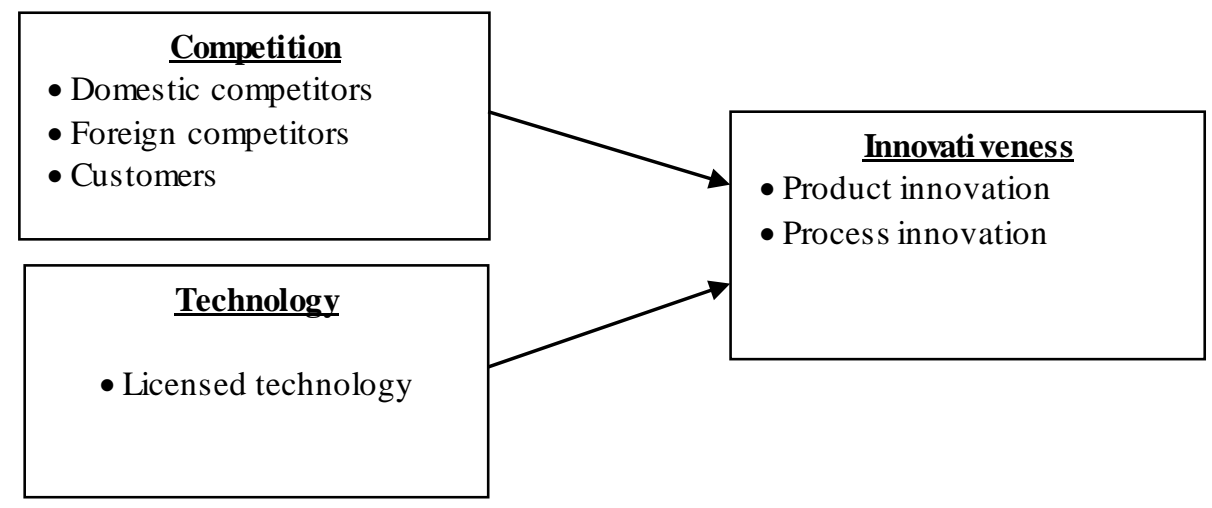

\section{Figure 1. Research Model Of The Study}

Hypothesis 1: A company that has a technology licensed from a foreign-owned company is likely to be innovative.

Hypothesis 2: A company who operates under pressure of competition is likely to be innovative.

Hypothesis 2a: A company who are under pressure from domestic competitors is likely to be innovative.

Hypothesis $2 \mathrm{~b}$ : A company who are under pressure from foreign competitors is likely to be innovative.

Hypothesis 2c: A company who are under pressure from customers is likely to be innovative.

Hypothesis 3: A company that has a technology licensed froma foreign-owned company and also operates under pressure of competition is likely to be innovative.

\section{Sample And Procedure}

The hypotheses are tested by utilizing the data in Business Environment and Enterprise Performance Survey conducted by World Bank. The survey provides a wide range of data regarding to financing, laboring, infrastructure, training, innovation, quality, technology etc. related is sues in 29 economies located in the region of Europe and Central Asia. It is a periodic survey, which is last updated in 2009 (The World Bank, 2009). The data used in this study is collected from 1152 Turkish companies in 2008. Eight hundred and sixty of these 1152 operate in manufacturing industry, 165 in service industry and others in core industry.

In some questionnaire forms, there are some missing values due to lack of knowledge, declining to give any response or because of any other reas on. The most common approach to missing data is list wise deletion, which means omitting the cases with missing data and running the analyses with what remains. List wise deletion often results in a decrease in the sample size. Since the sample size is big enough, this approach is chosen.

\section{MeASURES}

All factors investigated in the conceptual model, variables used in measuring these factors and scales used for the items are provided in Table 1. 


\section{Table 1. Factors And Related Variables And Scales}

\begin{tabular}{lll}
\hline Factor & Variable & Scale \\
\hline Technology & Use of any licensed technology from abroad & 1: Yes \\
& & 2: No \\
\hline Competition & Pressure to innovate from domestic competitors & 1: Yes \\
& Pressure to innovate from foreign competitors & $2:$ No \\
& Pressure to innovate from customers & \\
\hline Innovativeness & & $1:$ Yes \\
\hline - Product innovation & Introduction of a new product or service within the last 3 years & 2: No \\
& & 1: Yes \\
& & $2:$ No \\
\hline - Process innovation & Upgrade of an existing product line or service within the last 3 years & \\
& &
\end{tabular}

\section{Findings}

The data retrieved from the survey are analyzed statistically. After list wise deletion, the sample size remains 821 and all of them have been operating in manufacturing sector. For evaluating firm specific characteristics, frequencies are used and these characteristics are summarized in Table 2.

Table 2. Demographic Characteristics Of The Sample

\begin{tabular}{lll}
\hline & Frequency & Percent \\
\hline Industry & 149 & 18.15 \\
Food & 167 & 20.34 \\
Textiles & 120 & 14.62 \\
Garments & 100 & 12.18 \\
Chemicals & 37 & 4.51 \\
Plastics \& rubber & 104 & 12.67 \\
Non-metallic mineral products & 16 & 1.95 \\
Basic metals & 29 & 3.53 \\
Fabricated metal products & 31 & 3.78 \\
Machinery and equipment & 11 & 1.34 \\
Electronics & 57 & 6.94 \\
Other manufacturing & & \\
\hline Firm Age & 201 & 24.48 \\
\hline 1-10 years & 329 & 40.07 \\
11-20 years & 169 & 20.58 \\
21-30 years & 122 & 14.86 \\
\hline Firm mize years & & \\
\hline Small Sized Enterprises & 221 & 26.92 \\
Medium Sized Enterprises & 336 & 31.56 \\
Large Sized Enterprises & 264 & \\
\hline
\end{tabular}

Since the dependent variable is a yes/no question which means it is a dichotomous variable, we decide to focus on logistic regression analysis which is an optimal method for the regression analysis of dichotomous (binary) dependent variables (Allison, 2012). Before giving the results of logistic regression analysis, the correlations between variables are illustrated in Table 3.

Table 3. Descriptive Statistics

\begin{tabular}{llllllll}
\hline & Variable & Mean & $\begin{array}{l}\text { Std. } \\
\text { dev. }\end{array}$ & $\mathbf{1}$ & $\mathbf{2}$ & $\mathbf{3}$ & $\mathbf{4}$ \\
\hline 1 & Technology & 1.76 & 0.43 & 1 & & & \\
2 & Pressure from domestic competitors & 2.70 & 0.96 & -0.022 & 1 & & \\
3 & Pressure from foreign competitors & 2.33 & 1.12 & $-0.100^{* *}$ & $0.235^{* *}$ & 1 & \\
5 & Pressure from customers & 2.99 & 0.89 & -0.068 & $0.345^{* *}$ & $0.270^{* *}$ & 1 \\
\hline **: Significant at the 0.01 level & & & & & & &
\end{tabular}


Tables 4 and 5 show the results of logistic regression analysis. In Model 1, the effect of certified technology on innovativeness is investigated. In hypothesis 1 we argue that a firm with a licensed technology from a foreignowned company is likely to be innovative. Also, in Model 1 we find that having a licensed technology affect the likelihood of introducing a new product or service and/or upgrading of an existing product line or service. Thus Hypothesis 1 is supported.

Table 4. Logistic Regression Analysis Results For Model 1 And Model 2

\begin{tabular}{|c|c|c|c|c|c|c|c|c|}
\hline & \multicolumn{4}{|c|}{ Model 1} & \multicolumn{4}{|c|}{ Model 2} \\
\hline Variable & B & S.E. & Wald & $\begin{array}{l}\operatorname{Exp} \\
(\beta)\end{array}$ & B & S.E & Wald & $\begin{array}{l}\operatorname{Exp} \\
(\beta)\end{array}$ \\
\hline Technology & 0.758 & 0.196 & $14.948 * * *$ & 2.133 & & & & \\
\hline $\begin{array}{l}\text { Pressure to innovate from domestic } \\
\text { competitors }\end{array}$ & & & & & 0.087 & 0.086 & 1.032 & 1.091 \\
\hline $\begin{array}{l}\text { Pressure to innovate from foreign } \\
\text { competitors }\end{array}$ & & & & & -0.227 & 0.072 & $9.939 * * *$ & 0.797 \\
\hline Pressure toinnovate from customers & & & & & -0.159 & 0.092 & 2.995 & 0.853 \\
\hline$\overline{\mathbf{R}^{2}(\text { Nagelkerke })}$ & \multicolumn{4}{|l|}{0.028} & \multicolumn{4}{|l|}{0.027} \\
\hline $\mathbf{R}^{2}($ Cox\&Snell $)$ & \multicolumn{4}{|l|}{0.020} & \multicolumn{4}{|l|}{0.019} \\
\hline$-2 \mathbf{L L}$ & \multirow{2}{*}{\multicolumn{4}{|c|}{$\begin{array}{l}1010.414 \\
\chi^{2}=16.296, p=0.001, \text { d.f. }=1\end{array}$}} & \multirow{2}{*}{\multicolumn{4}{|c|}{$\begin{array}{l}1010.664 \\
\chi^{2}=16.046, p=0.001, \text { d.f. }=2\end{array}$}} \\
\hline & & & & & & & & \\
\hline
\end{tabular}

Table 5. Logistic Regression Analysis Results For Model 3 And Model 4

\begin{tabular}{|c|c|c|c|c|c|c|c|}
\hline \multirow[b]{2}{*}{ Variable } & \multicolumn{3}{|l|}{ Model 3} & \multicolumn{4}{|c|}{ Model 4} \\
\hline & S.E. & Wald & $\operatorname{Exp}(\beta)$ & $\boldsymbol{\beta}$ & S.E. & Wald & $\begin{array}{l}\operatorname{Exp} \\
(\beta)\end{array}$ \\
\hline $\begin{array}{l}\text { Technology } \\
\text { Pressure to innovate from } \\
\text { domestic competitors }\end{array}$ & & & & 0.707 & 0.197 & $12.187 * * *$ & 2.028 \\
\hline $\begin{array}{l}\text { Pressure to innovate from } \\
\text { foreign competitors } \\
\text { Pressure to innovate from } \\
\text { customers }\end{array}$ & -0.242 & $12.574 * * *$ & 0.785 & -0.220 & 0.069 & $10.193 * * *$ & 0.803 \\
\hline $\mathbf{R}^{2}$ (Nagelkerke) & 0.022 & & & 0.045 & & & \\
\hline $\mathbf{R}^{2}($ Cox\&Snell $)$ & 0.015 & & & 0.032 & & & \\
\hline$-2 \mathrm{LL}$ & 1010.664 & & & 1000.0 & & & \\
\hline & $\chi^{2}=12.785, p=0.00$ & d.f. $=1$ & & $\chi^{2}=26$. & $6, p=0$ & 1, d.f. $=2$ & \\
\hline
\end{tabular}

Hypothesis $2 \mathrm{a}$ suggest being under pressure to innovate from domestic competitors influences the likelihood firms will decide either be innovative or not. While hypothesis $2 b$ is investigating the effect of foreign competitors, hypothesis $2 \mathrm{c}$ is related with the pressure of customers. Interestingly, we could not find significant evidence that neither the pressure of domestic competitors nor the customers influence the decision of being innovative. The only determinant here is the foreign competitors. Thus hypothesis 2 is partially supported. The variables related with hypothesis $2 \mathrm{a}$ and $2 \mathrm{c}$ are removed from the next model and the results are shown.

The results regarding to Model 3 demonstrate that both having a licensed technology and being under pressure by foreign competitors influence the likelihood firms will decide either being innovative or not. Since the results are significant in the expected direction Hypothesis 3 is also supported.

\section{CONCLUSION AND FUTURE RESEARCHDIRECTIONS}

The primary aim of this study is to deal with the need for a model looking into the relationships between technology, competition and innovativeness as a whole. Therefore this study has implications for operation and IT managers in firms since both competition and technology have vital importance for them. Obviously, this study signifies the role of technology and innovativeness in companies. It means if companies may control the pressures in the market and adopt new technologies they will become more competitive or maintain their competitiveness.

According to this aim, in this study, a literature review about technology, competition and innovativeness, and the relationships between themis conducted. Based upon the literature survey, it is realized that there are few studies in the literature related to the relationships between technology and innovativeness, and competition and innovativeness, and also there are just a few studies conducted in Turkey concerning to this topic. Therefore another contribution of this study may be drawing out the point of view of Turkey about those issues. 
The research was conducted based upon the data gathered from Business Environment and Enterprise Performance Survey (BEEPS) conducted by World Bank. For analyzing data SPSS 16.0 is used and the model is tested by conducting several statistical tests and techniques. The data is collected from 1152 Turkish companies, and 860 of these 1152 companies are operating in manufacturing industry. Since there are some missing values in some questionnaires, first list wise deletion approach is applied to the data. The cases with missing data are omitted and the analyses are run based on the remaining 643 questionnaire forms. After that frequency analysis are conducted and then logistic regression analysis was done. Based upon the regression analysis, we find a strong relationship between having a technology licensed from a foreign-owned company and being innovative. We also see that if a company has a technology licensed from a foreign-owned company and operates under competitive pressure, it is likely to be innovative. However, this study provides an interesting finding that helps to understand the perception of Turkish manufacturing companies aboutcompetitive pressures in the market. When we test the relationship between competitive pressures and innovativeness, the only determinant of this relationship was found as the pressure that comes from foreign competitors which is a result of globalization.

While this study presents some important findings about this field, more research is definitely called for to develop this study. First, this study focuses on a single country, Turkey, and therefore future studies could make a comparison among two or more countries. Moreover, since the study is conducted in an emerging country, another option will be making an investigation of the relationship between competition, technology and innovativeness in both emerging and developed countries comparing them. This study has identified certain variables for each construct but some other variables may be required to investigate the relationship deeply. Further, since this study relies on a survey conducted by World Bank, future research could employ in -depth interviews which could enhance the quality of the survey. 


\section{REFERENCES}

Allison, P. D. (2012), Logistic Regression Using SAS, SAS Institute Inc., US.

Brady, G., Clauser, H. R. and Vaccari, J. A. (1997), Materials Handbook : An Encyclopedia for Managers, Technical Professionals, Purchasing and Production Managers, Technicians, Supervisors, and Foremen, New York: McGraw-Hill.

Erensal, Y. C., Öncan, T. and Demircan, M. L. (2005), Determining Key Capabilities in Technology Management Using Fuzzy Analytic Hierarchy Process: A Case Study of Turkey, Information Sciences, 176, 18, pp. $2755-2770$

Ethier, W. J. (2005), Globalization, Globalisation: Trade, Technology, and Wages, International Review of Economics and Finance, 14, pp. 237-258.

Hipkin, I. and Bennett, D. (2003), Managerial Perceptions of Factors Influencing Technology Management in South Africa, Technovation, 23, pp. 719-735.

Hsuan, J. (1999), Impacts of Supplier-Buyer Relationships on Modularization in New Product Development, European Journal of Purchasing \& Supply Management, 5, pp. 197-209.

Kalkan, A., Bozkurt, Ö. Ç., and Kılınç, O. (2012), The Relationships between Sector where SMEs Operating, and Their Strategies, Innovation Types and Innovation Barriers, Journal of Global Strategic Management, 6, 2, pp. 103-112.

Kocoglu, I., Imamoglu, S. Z., and Ince, H. (2011). The Relationship between Organizational Learning and Firm Performance: The Mediating Roles of Innovation and TQM, Journal of Global Strategic Management, 9, 3, pp.72-88.

Koufteros, X.A., Vonderembse, M.A. and Doll, W. J. (2002), Examining The Competitive Capabilities of Manufacturing Firms, Structural Equation Modeling, 9, 2, pp. 256-282.

Krishnamacharyulu, C. S. G. and Ramakrishnan, L. (2008), Management of Technology, Mumbai (India): Himalaya Pub. House.

Munir, K. A. (2003), Competitive Dynamics in Face of Technological Discontinuity: A Framework for Action, Journal of High Technology Management Research, 14, pp. 93-109.

Nedelko, Z., and Potocan, V. (2010), How to Improve Innovativeness of Small and Medium Enterprises. Journal of Global Strategic Management, 7,pp. s18-29.

Prajogo, D. I. and Sohal, A. S. (2004), The Multidimensionality of TQM Practices in Determining Quality and Innovation Performance - An Empirical Examination, Technovation, 24, pp. 443-453.

Reddy, P. (1997), New Trends in Globalization of Corporate R\&D and Implications for Innovation Capability in Host Countries: A Survey from India, World Development, 25, 11, pp. 1821-1837.

Rungtusanatham, M. and Forza, C. (2005), Coordinating Product Design, Process Design, and Supply Chain Design Decisions Part A: Topic Motivation, Performance Implications, and Article Review Process, Journal of Operations Management, 23, pp. 257-265.

Samaddar, S. and Kadiyala, S. (2006), Information Systems Outsourcing: Replicating an Existing Framework in a Different Cultural Context, Journal of Operations Management, 24, 6, pp. 910-931.

Schilling, M. (2005), Strategic Management of Technological Innovation, McGraw-Hill/Irwin.

Schumpeter, J. A. (1947), The Creative Response in Economic History. The Journal of Economic History, 7, 2, pp.149-159.

Teitel, S. (2005), Globalization and Its Disconnects, The Journal of Socio-Economics, 34, pp. 444-470.

Tracey, M., Vonderembse, M. A. and Lim J. (1999), Manufacturing Technology and Strategy Formulation: Keys to Enhancing Competitiveness and Improving Performance, Journal of Operations Management, 17, pp. 411428. 
Trott, P. (2008), Innovation Management and New Product Development. Prentice Hall.

Tseng, Y. H. (2006), Examining the Relationship between the Design-Manufacturing Cooperation and New Product Development Time Performance: The Moderating Role of Technological innovativeness, Journal of American Academy of Business, 9, 1, pp. 133-138.

Ussahawanitchakit, P. (2008), Impacts of Organizational Learning on Innovation Orientation and Firm Efficiency: An Empirical Assesment of Accounting Firms in Thailand, International Journal of Business Research, 8, 4, pp. 1-12.

Zehir, C., Muceldili, B., Akyuz, B., and Celep, A. (2010), The Impact of Information Technology Investments on Firm Performance in National and Multinational Companies, Journal of Global Strategic Management, 7, 1, spp. 143-154.

Zhang, Q., Vonderembse, M. A. and Lim, J. (2003), Manufacturing Flexibility: Defining and Analyzing Relationships among Competence, Capability, and Customer Satisfaction, Journal of Operations Management, 21, 2, pp. 173-191. 